\title{
Religious Education as a PREVENTION OF LEARNED HELPLESSNESS AND DEPRESSION: THEORETICAL CONSIDERATION
}

\author{
Vadim S. Rotenberg* \\ Tel-Aviv University, Bat-Yam, Israel
}

\begin{abstract}
In comparison to the expected outcome of the long lasting suppression and persecution, Jews during centuries demonstrated the relative resistance to stress, learned helplessness and depression.

This article suggests that this resistance may be related to the peculiarity of the traditional Jewish religious education that stimulates intellectual search activity as well as right-hemispheric polysemantic thinking in equilibrium with the left hemispheric verbal thinking.
\end{abstract}

Key words: Depression; Helplessness; Stress; Stress Resistance; Jewish Religious Education

\section{INTRODUCTION}

This article does not represent original experimental investigations of the relationships between Jewish religious education and depression in Jews. It is also not a comprehensive review of the literary data related to this topic just because articles about depression in Jews, even those that are discussing the role of religion, do not take into consideration the peculiarity of the education in Judaism in its relation to the psychological and brain mechanisms that can protect subject from depression. I have already published experimental investigations, review and theoretical discussion of some of these mechanisms (Rotenberg, 2004, 2009, 2011; Rotenberg \& Cholostoy, 2004) and now I am going to start with a short summary of these publications.

Martin Seligman (1975) proposed learned helplessness to be a general psychobiological state that predisposes subject to depression. From my point of view, the essence of learned helplessness as an outcome of numerous failures in attempts to achieve important goals and desires is renunciation of search. By search activity is understood activity designed to change the situation or the subject's attitude to it in the absence of a definite forecast of the results of such activity but with constant monitoring of the results at all stages of activity (see Rotenberg, 2009). According to the results of the experimental investigations, renunciation of search predisposes animals and humans to psychosomatic disorders. In animals it may assume the form of freezing while in humans it represents itself in depression and maladaptive anxiety. In the context of the present topic of discussion it is especially

"Correspondence to: Vadim Rotenberg, email: vadir@post.tau.ac.il

Received January 13, 2012; accepted January 21, 2012; Act Nerv Super (Praha) 54(1-2), 1-9. 
important that in humans exists a positive feedback between search activity and self-esteem (Rotenberg et al., 1996; Rotenberg, 2009). Search activity requires from the subject hard efforts in indefinite situation and in front of obstacles and is often accompanied by temporary failures. The process of search activity, irrespective of its pragmatic outcome, prevents helplessness and increases subject's resistance to stress and body resistance to any noxious factors. Search activity may be accompanied by the positive as well as negative emotions, and the type of emotion is less important than the process of search.

Long lasting easy and invariable achievements with the total predictability of the results do not require search activity and decrease its level, as well as the resistance to learned helplessness in future in front of obstacles. At the same time, a training of search activity from childhood increases the subject's resistance to invariable failures. Speaking metaphorically, irrespective of what fuels the fire in the hearth (search activity) it is the fire, not the fuel that matures.

High self-esteem prevents in difficult situations the surrender reaction and triggers the continuation of search. On the other hand, search activity in the indefinite and even dangerous situation, the readiness to cope with obstacles, to overcome failures and not to give up increases self-esteem and it also helps to prevent depression.

Now let us turn to another very important psychological mechanism that protects mental health only in humans. Humans are often suffering from a special form of stress that can cause helplessness, renunciation of search and depression. It is an inner motivational conflict between opposite behavioral attitudes, opposite views on environment, on the world that is polydimensional and includes many contradictions. A simultaneous tendency to approach something that looks out as very desirable and to avoid it because it does not correspond to the subject's Self-Image causes a strong emotional tension and may block any constructive activity and finally lead to depression. The repression of a strong however unacceptable for the consciousness motivation displays renunciation of search specific for humans. It is a renunciation of search for the realization of this unacceptable motive in an overt behavior as well as renunciation of an attempt to integrate this motive with other acceptable motives.

Healthy adults have a special brain mechanism that provides a very specific integration of the conflicting motives and of the formally incompatible information that provokes such conflicts. It is the ability of the right frontal lobe to create a polysemantic context - the highest skill of human's brain (see Rotenberg, 2004). However, this mechanism has to achieve its full functional efficiency in the process of the upbringing and education. It is a long-lasting process that requires special attention and directed activity of parents and teachers. Until this very delicate mechanism become totally matured it is very vulnerable to all disturbing patterns, both physical and mental, and the functional insufficiency of this mechanism is a predisposition towards mental disorders and especially towards depression because it does not help to solve inner conflicts and prevent repression (Rotenberg, 2009).

On the other hand, search activity by itself is enhanced by confronting the complex reality and open tasks that do not have a sole solution. It means that search activity and polysemantic way of thinking supplement each other in the process of coping with difficult problems. The polysemantic image thinking during the dream state (in REM sleep) is an important reservoir for the alternative search activity which helps to restore this activity after giving up in the previous period of wakefulness (Rotenberg, 2009).

\section{DEPRESSION IN JEWS}

Now let us turn to the main topic of this article. The most publications that compare the distribution of depression in Jews and non-Jews and the role of Judaism vs. other religious affiliations, do not take enough into consideration neither a very specific fate of Jews during the recent 2000 years nor the specific feature of Jewish religious education. During the almost all history of dispersion, in diaspora, Jews were surrounded by foreign ethnic and religious 
groups that in the best case avoided them and usually were hostile to them and persecuted them while Jews were unable to defend themselves. In this condition the development of learned helplessness and depression is very expected. Of course, up to the modern time there were no scientific investigations of the representation of depression in Jews in comparison to other nations, however it is obvious that Jews survived in these very hard conditions and their intellectual and behavioral activity in any available direction was very high during centuries. Their achievements were provocative for anti-semitism however their achievements, activity and creativity in different domains would be impossible if they would suffer in mass from learned helplessness and low self-esteem.

As soon as the persecution of Jews stopped and they were able to leave Ghetto their investments in different domains (science, art, business, medicine etc.) became disproportionally high and it is an additional sign that in all generations most of them were free from learned helplessness. If depression and learned helplessness would be prominent in Jews during a very long period of persecution and restrictions of human rights they would be unable to display such activity and creativity. According to Pearl (1996) Jews endured the stress and unemployment of Great Depression in USA better than other ethnic groups. And of course being predisposed to learned helplessness and depression they will be unable just after the Second World War and the general national tragedy of Holocaust, in a very uncertain situation to create the State of Israel and to win a war with surrounding Arabic armies.

However, after such a long history of persecution it would be quite expectable to find the relative increase of depression in Jews and it was really found in some investigations. Jews had higher prevalence of major depression than Catholics, Protestants and no-Jews (Levav et al., 1997). In a review performed by McCallough and Larson (1999) is emphasized that according to some investigations Jews have elevated risk for depressive disorders. It is necessary to take into consideration that most of these investigations used clinical population (see later), however even in some studies using different community samples Jews had a twofold risk for major depression in comparison to other religions. Among the adults who were not depressed at baseline but became depressed by the 24-th month follow-up Jews were over-represented (see McCallough \& Larson, 1999).

However, this finding was not confirmed in some investigations. Idler and Kasl (1992) found that being Jewish even lower (!) risk of developing depression over a 3 year follow up period relative to Catholics. Rosmarin, Porgament and Mahoney (2009a) after investigating a large Jewish community samples come to the conclusion that global Jewish religiousness without differentiation between its levels was on the whole unrelated to mental health functioning, but higher trust in God was associated with less anxiety and depression and greater happiness, what was opposite to mistrust. These data confirm for Jews data of negative relationships between religious attitudes and depression in other religions (Nelson, 1989; Smith et al., 2003, Ross, 1990, McCullough \& Larson, 1999).

In the comprehensive historical review of affective disorders among Jews (Kohn et al., 1999) was shown that $56 \%$ of all studies performed in this direction indicated that Jews had higher rates of affective disorders than non-Jews what is quite expectable in the context of the history of persecution. However, it means also that in many investigations this difference was not found and at least it was not robust. Across all studies Jews had a $20 \%$ greater risk for affective disorders than non-Jews. In some studies was found even a lower rate of affective disorders for Jews. It is quite understandable that in most of the investigations of the European Jews (that have been especially strong persecuted in the 20-th Century and in previous centuries) the risk of mental and affective disorders was higher than in non-Jews (see McCullough \& Larson 1999), however even on this population it was not confirmed by some investigators (see Kohn et al. 1999).

Data of investigations performed in USA are also contradictive. Not all of them confirmed that Jews are more often suffering from affective disorders although most of the USA Jews were new immigrants. Authors proposed that the relatively increased proportion of Jewish 
in-patients may reflect not the increased number of sick persons but the Jewish predisposition towards treatment, their attention to their health (see Kohn et al., 1999). In the investigations performed in East London Jewish and non-Jewish patients (Fernando, 1978, see Kohn et al., 1999), the similarities between Jews and non-Jews were more striking than the differences. Author stressed that paternal inadequacy might be a factor influencing depression in Jews, like maternal dominance ("Jewish mother") and father weakness. At the same time, author (Fernando) found that weakness of ethnic links, marginality and decreased religiousness were related to depression in Jews and he proposed that Jewish religion may be helpful in reducing vulnerability to depression. This idea is important for the topic of the present article.

According to some investigations (Rosenberg, 1962) children reared in neighborhoods that were similar to them in terms of religious affiliation (it means, in traditional Jewish neighborhood) had lower level of depression affect than adolescents raised in religious dissimilar neighborhood. It may be an outcome of the more psychological comfort when Jewish children are surrounded by people of similar religious affiliation, but it may be also a direct influence of religion and religion education by itself that is stronger in such communities.

Some recent investigations show (Wang et al., 2008) that mean score of the depression (BDI) in Jewish and non-Jewish sample is almost equal (9.0 and 8.6). Frequency of depression was $5.1 \%$ for Jews and $6.3 \%$ for non-Jews.

Levav et al. (1977) have shown the increased risk for affective disorders only in Jewish men while the proportion of depressed women was equal in Jews and non-Jews. It is a very interesting finding that stimulated a discussion in scientific publications because in the nonJewish population the proportion of depressed women to depressed men is usually 2:1 (Weissman et al., 1984). In Jews depression was almost equally distributed between genders (Weissman \& Klerman, 2002). While comparing Jews and non-Jews, authors have shown that it was no differences in depression rates among women no matter what their religious affiliation was. At the same time depression rates for Jewish men were twice higher than for non-Jewish men. Kohn et al. (1999) also confirmed that Jewish men display an increased risk for affective disorders, but according to these authors this risk was relatively low.

According to (Weissman \& Klerman, 1977) the increased amount of depression in Jewish men is related to the lower level of alcohol use in this population, in comparison to other ethnic groups. According to McCullough and Larson (1999) excess depression was attributed only to Jewish men. Combined prevalence of both depression and alcohol abuse together were not different for Jewish men vs. non-Jewish men. It is interesting that alcohol use among Jewish men was higher in Los Angeles (in the less traditional Jewish community) than in the New Haven where the community is more traditional: 2:1 female-male ratio of prevalence rates for depression was obtained in the more secular community of Los-Angeles in comparison to 1:1 ratio in New Haven. According to Levav and Kohn (1997) in New Haven the period prevalence of major depression for males was even higher than for females (18.6\% vs. $9.8 \%)$.

It was shown on other populations that abstinence from alcohol correlates with high depression rates. It means that alcohol use may mask depression in the non-Jews communities, and it does not mean that Jewish men are less healthy and non-Jewish men are more healthy because alcohol addiction may have the same roots (like helplessness) as depression. Study of young adults in Israel where rates of alcohol dependency are low, have shown equal rates of depression among Jewish women and men (Levav et al., 1993). Probably in non-Jews the predisposition towards depression in males is partly masked or displaced by alcohol addiction. Amish, a population that does not drink presents high rates of depression equal in women and men (Weissman \& Klerman, 1977). However, alcoholism may be not the only reason for differences between genders in affective disorders in the nonJewish population. 
According to Wang et al. (2008) frequency of depression for Jewish girls and boys was not very different $-5.5 \%$ and $4.6 \%$. For non-Jewish girls and boys it was $8.4 \%$ and $4 \%$. Female/male ratio in Jews was 1.2, in non-Jews 2.1. From my point of view, it is a big question whether the difference between genders in the non-Jewish adolescents can be explained by the alcoholism of boys, in any case it requires special investigations. I propose that such difference in the distribution of depression between genders can be partly explained by the difference in brain maturation. Women are characterized in general by the more speed maturation of the right frontal lobe (Saugstad, 1998). As a result it is characterized by the less developed functional ability, because the longer is the process of maturation the more high functional level is achieved (see Rotenberg, 2004). This brain structure is responsible for integration of the conflicting emotional experiences into the holistic polysemantic context that provides psychological adaptation to all possible contradictions of the polydimensional world, especially to the world of human relationships (Rotenberg, 2004).

Males have greater right-ward lateralization of long-range brain connectivity in superior temporal, inferior frontal and inferior occipital cortex while females have greater left-ward lateralization of long-range connectivity in the inferior frontal cortex (Tomasi \& Volkow, 2011). Due to this rightward lateralization males may be less vulnerable to emotional disorders, and females with their greater leftward lateralization are characterized by the higher verbal skills. However, investigations in Israel indicated male advantage in verbal skills (Maccoby \& Jacklin, 1976, see Safir, 1986). At age 9 Jewish boys begin to surpass girls on the verbal subtest (Lieblich, 1985). Orthodox Jewish boys are more successful than girls in verbal tests. This difference was less prominent in Kibbutz (see Safir, 1986) where the education was usually less traditional. Thus it is reasonable to suggest that these increased verbal skills in Jewish boys are related to the specificity of Jewish religious education. However it is reasonable to propose that it was achieved not on the expense of the right hemispheric skills (see the next part of the article). The peculiarity of the Jewish traditional education allows to speculate that the moderate level of depression in Jews (in comparison to the expected one according to the long lasting fate) as well as almost equal distribution of depression between genders in Jews may be caused not only by the absence of alcoholism in Jewish men.

The influence of the religion on mental health depends also on the formal vs. informal religious involvement. McCullough and Larsen (1999) performed comparison between Christians and Jews. In Christians involvement in formal religious activity was negatively associated with somatic- retarded depressive symptoms at the 7-year follow up. Among Jews, however, formal religious involvement at baseline had a positive net association with somatic-retarded depressive symptoms and with depressed affect at the 7-year follow up. In contrast, participation in informal church groups was associated with lower level of depression for Jews and with higher level of depression among Christians. Does it mean that for Christians it is more important to feel that they belong to the special social group, to the Church with all its collective actions, while for Jews is more important the individual spiritual experience? It may relate to the protective influence of the intrinsic motivation towards religion.

Another interesting problem is the influence of spiritual struggles (tension in regard to spiritual issues) on the subject's affective state. It was shown (Rosmarin, Pargument \& Flanelli, 2009b) that on its highest level spiritual struggles are working in Orthodox Jews in a different way in comparison to other groups of religious persons. Usually it is a risk factor for health that predisposes subjects to anxiety and depression when they feel guilty and ashamed in the process of such struggles, especially among individuals with a high level of personal religiousness. However in Orthodox Jews it paradoxically increased physical and mental health. At the same time, in Orthodox Jews like in the members of other religions, negative religious coping like anger on God and religious disengagement correlate with depression and anxiety (Pirutinsky et al., 2011). It means that negative religious coping in 
Orthodox Jews also leads to the disturbance of self-identification. So why Orthodox Jews are more resistant to spiritual struggles? I suppose that in Orthodox Jews these struggles do not cause inner conflicts and doubts in the fundamental religious values but display an active intellectual fight with a high level of search activity, like in every strong intellectual activity. The religious values of these Jews are strong enough and related to the most important part of their self-identification that cannot be disturbed by any spiritual struggle, and at the same time the traditional Jewish religious education trains and predisposes subject to such struggles.

\section{THE PECULIARITY OF THE JEWISH RELIGIOUS EDUCATION}

Now we come to the central point of this presentation - to the essence of the system of the classical Jewish religious education. First of all, such education is characterized by the stimulation of the intellectual activity from early childhood. Talmud that Jewish children are studying is not a collection of the irrefutable truth and final answers on the basic questions. Talmud is not a collection of dogmatic statements. It contains collisions of different interpretations and opposite approaches to the same objects, events and statements. In contrast to the typical Western education, secular or religious, Jewish traditional education teaches a flexible approach to the most complicated problems of human existence, including spiritual life. As a result, a child learns to accept contradictory and controversial explanations regarding the fundamental laws of ethical conduct, as they appear in different biblical commentaries. Of course, they are some basic statements that are out of discussion, like presence of God and main spiritual values but many other statements are free from being dogmatic. A pupil has to choose his own position in the numerous discussions, as if he is a co-author of commentary, and it is a very active position full of personal responsibility. The Talmudic student is trained not to learn by heart the irrefutable truth (as happens in most other systems of education), but to search for this truth using different positions and arguments, and to appreciate the conclusion that is neither the final nor the sole truth. It is a natural stimulation of search activity. It is a strong spiritual struggle! What is only recently recognized in Western education and science as a method for the development of creativity was already used long ago in the process of education in small Jewish villages. Is it not a root of the high number of Nobel Prices?

The ability to see the same object from different and even opposite points of view is a sign of the polysemantic right-hemisphere thinking. However it is achieved not on the basis of image thinking, like in Eastern cultures. Jewish culture is first of all a verbal culture, the culture of Bible, and verbal activity is in the competence of the left hemisphere. It can explain the above mentioned high verbal skills in Jewish males from adolescence. What is really unique, in Bible and in Talmud the text is used for the creation of the polysemantic context. Thus, according to the peculiarity of Jewish culture, both hemispheres are maintained in balance, which is important for adaptation, for solving emotional conflicts and for the actualization of search activity.

The essence of studying the Talmud is best expressed in the following story or parable.

One day a gentile came to a learned Jew and said he wished to study the Talmud. The Jew replied: "Jews study the Talmud from childhood". "But I want to try", said a gentile. "Surely my powers of understanding are no worse than those of Jewish children?' The Jew replied: "Very well. But first answer these questions. Number one: two Jews fell down a chimney. One came out covered in soot, the other was clean. Which one went to wash?" "The dirty one, of course!" "Wrong. The one covered in soot looked at the clean one and thought he was clean, too, and didn't need a wash. While the clean one looked at the other, he was horrified at what he saw and ran off to wash. Now, question two; two Jews fell down a chimney. One came out covered in soot, the other was clean. Which one went to wash?" "But I already know the answer to that. The clean one, naturally." "Not so. The words may be the same, but 
the questions are different. It is the dirty one who goes and has a wash. Because the clean one looks at the dirty one and thinks "I am as dirty as that dirty?", looks at himself in the mirror and sees that he isn't. While the dirty one looks at the clean one, refuses to believe that he himself could possibly look like that after falling down a chimney, looks in the mirror and goes and washes. Now for the third question: two Jews fell down a chimney. One came out covert in soot, the other was clean. Which one went to wash?' "The dirty one?" "Wrong". "The clean one, then" "Wrong again." "OK, what's the right answer?" "There isn't one, the question's wrong. It's quite impossible that two Jews should fall down a chimney and one come out covered in soot and the other be clean".

The permission to search for one's own way to the truth, along with the legitimization of the inevitable mistakes and errors, decreases the fear to be wrong and stimulates activity. The individual is building his own personality, in the process of developing search activity, and this process increases self-confidence and self-esteem. When the pupil discovers that the contradictory interpretations of the same objects and events are in a complementary relationships and it is truth beyond different approaches, that similar propositions can cause different outcomes, than he joins polydimensional reality.

Unfortunately, in the modern world, including the modern Jewish society this traditional style of Jewish education with all its advantages is partly lost, even in religious community. It may be one of the reasons why in some groups of Jews the level of depression is higher than in other groups and in non-Jewish communities. The principles of this education have to be extracted and used on the high level not only in religious but also in secular education. It is a very important task.

The absence of learned helplessness, the ability to survive, the absence of the expected tremendously high level of depression can be at least partly explained as a consequence of traditional Jew education which formed the style of Jewish thinking, Jewish humor and creativity in many previous generations. Also, in Judaism, man is not a slave of God, he is a partner and interlocutor of God and actively participates in his own personal development and self-realization. Humiliations and stressful life circumstances are unable to suppress search activity and self-confidence of a person who has felt himself from his childhood as a responsible partner to his God. In order to continue in the struggle against failures which at time appear hopeless, it is necessary to preserve high self-esteem and to be oriented with internalized values. This position was typical for Jews throughout their history. The estimation of previous achievements characterized even those Jews who did not feel strong relationships to Jewish traditions - it was something like social heredity coming from the family. It is well known that highly educated Jewish emigrants from Nazi Germany to Palestine, when working on a simple job, referred to one another as "Herr professor", "Herr Doctor", Herr lawyer" ... I suggest that it was not an identification with the lost profession (it could cause only depression), it was an identification with the previous achievements. This self-confidence helped them to survive during difficult times, to continue search activity, and finally to change their fate and the face of the country.

The traditional Jewish education helped to create a very peculiar mentality and psychology of Jews that was partly reproduced in the following generations through the mechanism of social heredity, from father to son. However, if in the future the crucial cornerstone of traditional Jewish education will be not restored, the mechanism of social heredity may eventually become exhausted.

\section{CONCLUSION}

Despite of the hard fate and long lasting persecution there are no remarkable and stable differences in the distribution of helplessness and depression between Jews and non-Jews. It must have some explanations. My proposition is that it is not only the outcome of the support of the religion by itself (a mechanism that is common for different religions and is 
not discussed in this article) but first of all of the peculiarity of Jewish traditional education that stimulates the polysemantic way of thinking while using not images but verbal constructions and providing the opportunity for the equilibrium between both hemisphere functions. This education also stimulates search activity. It is not exclusive advantage of Judaism - it's principles can be used in different systems of education.

\section{REFERENCES}

Fernando, S.J.M. (1978). Aspects of depression in a Jewish minority group. Psychiatria Clinica, 11, $23-33$.

Idler, E.L., \& Kasl, S.V. (1992) Religion disability, depression, and the turning of death. American Journal of Sociology, 97, 1052-1079.

Kohn, R., Levav, I., Zolondek, S., \& Richter, M. (1999) Affective disorders among Jews: a historical review and meta-analysis. History of Psychiatry, 10, 245-267.

Levav, I., Kohn, R., Dohrenwend, B.P., Shrot, P.E., Skodol, A.F., Schwartz, S., Link, B.G., \& Naveh, G. (1993). An epidemiologic study of mental disorders in 10-year cohort of young adults in Israel. Psychological Medicine, 23, 691-707.

Levav, I., Kohn R., Golding, J.M., \& Weissman, M.M. (1997). The vulnerability of Jews to affective disorders. American Journal of Psychiatry, 7, 941-947.

Lieblich, A. (1985). Sex differences in intelligence test performance of Jewish and Arab school children in Israel. In: M.P. Safir, M.S. Mednik, D. Izraeli, J. Bernard (Eds.) Women's worlds: From the new scholarship. New York: Praeger Publications.

Maccoby, E., \& Jacklin, C.N. (1974). The psychology of sex differences. Stanford: Stanford University Press.

McCullough, M.E., \& Larson, D.B. (1999). Religion and depression: A review of the literature. Twin Research, 2, 126-136.

Nelson, P.B. (1989). Ethnic differences in intrinsic/extrinsic religious orientation and depression in elderly. Archives of Psychiatric Nursing, 3, 199-204.

Pearl, L. (1996). Jews endured Depression better than others, scholar says. http:// www.iweekly.com/articles/full/3016..

Pirutinsky, S.., Rosmarin, D.H., Pargament, K.I., \& Mildlarsky, E. (2011). Does negative religious coping accompany, precede, or follow depression among Orthodox Jews? Journal of Affective Disorders, 132, 401-405.

Rosenberg, M. (1962). The dissonant religious context and emotional disturbance. American Journal of Sociology, 68, 1-10.

Rosmarin D., Pargament K., \& Mahoney A. (2009). The role of religiousness in anxiety, depression, and happiness in Jewish community sample: a preliminary investigation. Mental Health Religion Culture, 12, 97-113.

Rosmarin, D., Pargament, K., \& Flannelly K. (2009). Do spiritual struggles predict poorer physical/mental health among Jews? International Journal for the Psychology of Religion, 19, 244-258.

Ross, C.E. (1990). Religion and Psychological Distress. Journal for the Scientific Study of Religion, 29, 236245.

Rotenberg, V.S. (2004). The psychophysiology of REM sleep in relation to mechanisms of psychiatric disorders. In: A.Z. Golbin, H.V. Kravitz, L.G. Keith (Eds.) Sleep Psychiatry, Taylor and Francis, London pp. 35-64.

Rotenberg, V.S. (2004). The peculiarity of the right-hemisphere function in depression: Solving the paradoxes. Progress in Neuro-Psychopharmacology and Biological Psychiatry, 28, 1-13.

Rotenberg, V.S. (2009). Search activity concept: Relationship between behavior, health and brain functions. Activitas Nervosa Superior, 51, 12-44.

Rotenberg V.S., \& Cholostoy A. (2004) Behavioral attitudes in major depression: a pilot investigation. Homeostasis, 34, 54-58.

Rotenberg V.S., Tobin M., Krause D., \& Lubovikov I. (1996) Psychosocial problems faced during absorbtion of Russian-speaking new immigrants into Israel: A systematic approach. Israel Journal of Psychiatry and Related Sciences, 33, 40-49.

Safir, M.P. (1986) The effects of Nature or of Nurture on sex differences in intellectual functioning: Israeli findings. Sex Roles, 14, 581-590.

Saugstad, L.F. (1998) Cerebral lateralization and rate of maturation. International Journal of Psychophysiology, 28, 37-62. 
Seligman, M.E.P. (1975). Helplessness: On Depression, Development and Death, San Francisco: W.H. Freeman

Smith, T.B., McCullough, M.E., \& Poll, J. (2003). Religiousness and depression: Evidence for a main effect and the moderating influence of stressful life events. Psychological Bulletin, 129, 614-636.

Tomasi, D., Volkow, N.D. (2011). Laterality patterns of brain functional connectivity: Gender effects. Cerebral Cortex (in press), doi: 10.1093/cercor/bhr230

Wang, Y.P., Lederman, L.P., Andrade, L.H., \& Gorenstein, C. (2008). Symptomatic expression of depression among Jewish adolescents: Effects of gender and age. Social Psychiatry and Psychiatric Eepidemiology, 43, 79-86.

Weissman, M.M., \& Klerman, G.L. (1977). Sex differences and epidemiology of depression. Archives of General Psychiatry, 34, 98-11.

Weissman, M.M., Leaf, P.J., Holzer III, C.E., Myers, J.K., \& Tischler, G.L. (1984). The epidemiology of depression; an update on sex differences in rates. Journal of Affective Disorders, 7, 179-188. 